\title{
The Fear of Disease Progression, Emotional Distress, and Quality of Life Associated with Prostate Cancer Patients
}

\author{
Chang, Yuan-Ping 1 Lee, De-Chih 2* Cheng, Tse-Chou 3 Lee, Yi-Hua 4
}

1 Department of Nursing, Da-Yeh University, 168 University Road, Dacun, Changhua 51591, Taiwan (R.O.C.) 2 Department of Information Management, Da-Yeh University, 168 University Road, Dacun, Changhua 51591, Taiwan (R.O.C.)

3 Department of Urology, ChiMei Hospital, Liuying, 201, Taikang, Taikang Vil., Liuying Dist., Tainan City 73657, Taiwan (R.O.C.)

4 The National Health Research Institutes, 35 Keyan Road, Zhunan, Miaoli County 35053, Taiwan (R.O.C.)

\section{Introduction:}

Prostate cancer is a high incidence of cancer for men in 2015, with about 1.6 million new cases reported and a rate of increase of $66.1 \%$ during the past ten years. Cancer patients experience a great deal of psychological stress and physical discomfort resulting from treatments, which ultimately could affect the quality of life of patients and their families. Patients' perception regarding disease treatment and prognosis, as well as their own physical and mental indicators could offer medical care providers and patient themselves the bases for decision-making on future care and life quality.

Objectives:

This study aimed to compare the fear of disease progression, emotional distress, and quality of life in patients with prostate cancer and to understand the effect of different treatment methods on the fear of disease progression index, emotional distress and quality of life of patients with prostate cancer.

\section{Methods:}

Three therapy modules of treatments were employed in this study on prostate cancer patients: hormonal treatment (HT), a combination of hormone treatment with either chemotherapy, radiotherapy, or surgery (Mix Treatment), and placebo treatment on the control group (CG). The study was designed as a cross-sectional study of 38 patients for the diagnosis and treatment of prostate cancer.

Results:

By descriptive statistics, the control group scored better than the other two treated groups in emotional distress and quality of life, indicating that cancer treatment has a negative impact on patients' life or psychological status. These results also show that mixed treatment can indeed reduce cancer patients' fear of the disease progression.

\section{Conclusions:}

For cancer patients, quality of life can be used as an important indicator for evaluating health and medical measures.

Table 1. Post-Test Score Minus Pre-Test Scores

\begin{tabular}{|c|c|c|c|c|c|}
\hline & & mean & std & $\min$ & $\max$ \\
\hline \multirow{3}{*}{$\begin{array}{c}\text { Fear of } \\
\text { Disease } \\
\text { Progre } \\
\text { ssion }\end{array}$} & Control group & -2.67 & 4.44 & -13.00 & 1.00 \\
\hline & Mixed treatment & -7.42 & 12.57 & -34.00 & 2.00 \\
\hline & $\begin{array}{l}\text { Hormone } \\
\text { treatment }\end{array}$ & -1.24 & 3.85 & -9.00 & 8.00 \\
\hline \multirow{3}{*}{$\begin{array}{l}\text { Quality } \\
\text { of Life }\end{array}$} & Control group & 3.22 & 8.93 & -15.00 & 11.00 \\
\hline & Mixed treatment & -1.25 & 9.02 & -14.00 & 15.00 \\
\hline & $\begin{array}{l}\text { Hormone } \\
\text { treatment }\end{array}$ & 1.82 & 9.68 & -17.00 & 16.00 \\
\hline \multirow{3}{*}{$\begin{array}{c}\text { Emotio } \\
\text { nal } \\
\text { Distres } \\
\mathrm{s}\end{array}$} & Control group & -1.11 & 3.18 & -7.00 & 4.00 \\
\hline & Mixed treatment & -.25 & 2.56 & -5.00 & 5.00 \\
\hline & $\begin{array}{l}\text { Hormone } \\
\text { treatment }\end{array}$ & -.06 & 3.65 & -5.00 & 7.00 \\
\hline
\end{tabular}

